\title{
Lower serum sodium level predicts higher risk of infection-related hospitalization in maintenance hemodialysis patients: an observational cohort study
}

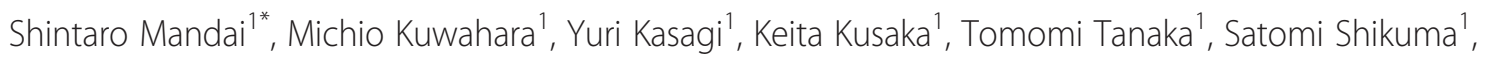
Wataru Akita ${ }^{1}$ and Sei Sasaki ${ }^{2}$

\begin{abstract}
Background: Hyponatremia is associated with increased mortality in chronic kidney disease with and without end-stage renal disease (ESRD). Increasing evidence suggests that hyponatremia is not only a marker of severe underlying disease, but also a direct contributor to mortality. However, specific pathogenesis or diseases contributing to mortality in the hyponatremic population are unknown. This study aimed to clarify the relationship between serum sodium level ( $\mathrm{sNa}$ ) and infection risk in ESRD patients.

Methods: This observational cohort study included 332 patients on maintenance hemodialysis in our dialysis unit in May 2009. The mean of 3 monthly measurements of glucose-corrected sNa before each dialysis session in May, June, and July 2009 was applied as baseline sNa. The primary endpoint was first infection-related hospitalization $(\mathrm{IRH})$, and the secondary endpoint was death of any cause. Data were analyzed using Cox hazards modeling, adjusted for baseline demographics and characteristics, or laboratory data. Patients were followed until transfer, kidney transplantation, death, or study end on January 31, 2013.

Results: Mean sNa was $138.9 \mathrm{mEq} / \mathrm{L}$ (1st tertile: <138.0, $n=104$; 2 nd tertile: 138.0-140.0, $n=116$; 3rd tertile: >140.0, $\mathrm{n}=112)$. During 39.5 months' mean follow-up, 57 patients experienced IRH $(56.4 / 1,000$ patient-years overall; $89.7 / 1,000$ in 1st tertile; 57.9/1,000 in 2nd tertile; 28.0/1,000 in 3rd tertile), and 68 patients died. The hazard ratio (HR) for IRH was higher for the 1st and 2nd tertiles than the 3rd tertile (unadjusted HR, 3.20; 95\% confidence interval $(\mathrm{Cl}), 1.54-6.64 ; \mathrm{p}=0.002$; adjusted $\mathrm{HR}, 2.36$; $95 \% \mathrm{Cl}, 1.10-5.04 ; \mathrm{p}=0.027$; and unadjusted $\mathrm{HR}, 2.07$; $95 \% \mathrm{Cl}, 0.98-4.40$; $\mathrm{p}=0.058$; adjusted $\mathrm{HR}, 2.11 ; 95 \% \mathrm{Cl}, 0.99-4.51 ; \mathrm{p}=0.054$ respectively). In a continuous model, higher sNa was associated with lower risk of $\mathrm{IRH}$ (adjusted $\mathrm{HR}, 0.90 ; 95 \% \mathrm{Cl}, 0.81-0.99 ; \mathrm{p}=0.040$ ), and lower all-cause mortality (adjusted HR, 0.91; 95\% Cl, 0.83-1.00; $\mathrm{p}=0.049$ ).
\end{abstract}

Conclusions: Lower sNa is an independent predictor of higher risk for infection-related hospitalization in maintenance hemodialysis patients. Infectious disease may partially account for the increased mortality observed in the hyponatremic population with ESRD.

Keywords: End-stage renal disease, Hemodialysis, Hyponatremia, Infection, Mortality

\footnotetext{
* Correspondence: shintaro_mandai@yahoo.co.jp

'Department of Nephrology, Shuuwa General Hospital, 1200 Yaharashinden, Kasukabe, Saitama 344-0035, Japan

Full list of author information is available at the end of the article
} 


\section{Background}

Hyponatremia is among the most common electrolyte disorders in clinical practice, particularly in hospitalized patients, $15 \%$ to $40 \%$ of whom have hyponatremia, depending on the definition [1,2]. The relationship between hyponatremia and increased mortality has been recognized, primarily in patients with heart failure and liver cirrhosis [3-7]. Recent studies have additionally revealed this association in a wide variety of diseases including myocardial infarction [2,8], pulmonary embolism [9], cancer $[2,10]$ and pneumonia [11], and in patients in perioperative settings $[1,12]$ and those in intensive care units [13]. Similar observations have been made in chronic kidney disease (CKD) patients with [14-16] and without end-stage renal disease (ESRD) [17]. These studies have identified hyponatremia as an independent predictor of mortality after adjustments for potential confounders reflecting severity of underlying disease, and thus suggested that hyponatremia is not only a marker of severe underlying disease, but also a direct contributor to mortality. However, it has yet to be clarified how hyponatremia contributes to mortality, or which disease is responsible for increased mortality in the hyponatremic population. Previous data which answer this question are very limited, but Waikar et al. [14] showed that the relationship between lower sNa and higher mortality was not significant in analyses of cardiovascular mortality, but rather, was significant in analyses of non-cardiovascular mortality in maintenance hemodialysis (HD) patients. We hypothesized that hyponatremia is associated with increased susceptibility to infection, and infectious disease additionally contribute to mortality in the hyponatremic population. This study aimed to investigate the relationship between $\mathrm{sNa}$ and the future risk of hospitalization due to infectious disease in patients with ESRD.

\section{Methods}

\section{Study population}

In May 2009, 381 patients underwent maintenance HD in our dialysis unit. The study participants included 354 patients whose HD vintage was 12 months or more. Participants were excluded if patients lacked at least one measurement among the 3 monthly routine laboratory measurements before each dialysis session in May, June, and July $2009(n=12)$, or an observational period was less than 6 months $(\mathrm{n}=10)$. The remaining 332 patients were enrolled in this study. All patients received thriceweekly HD. Cardiovascular disease (CVD) was defined as myocardial infarction, coronary revascularization, or hospitalization for heart failure. Peripheral vascular disease was defined as revascularization of arteries distal to the common iliac artery or amputation. Cerebrovascular disease was defined as cerebral infarction, cerebral hemorrhage, or subarachnoid hemorrhage. Chronic liver disease was defined as liver cirrhosis or chronic viral hepatitis. Dialysis vintage was defined as time from initiation of HD until May 1, 2009, or from that of peritoneal dialysis if patients had undergone peritoneal dialysis before switching to HD. Intradialytic weight loss (IDWL) (\% per body weight) was calculated according to an equation: IDWL $=$ intradialytic filtration volume in $\mathrm{kg} /$ post-dialytic body weight in $\mathrm{kg} \times 100$. In our dialysis unit, regular blood sampling was conducted monthly before the first dialysis session in a week (on Mon or Tue). The sNa was measured in our hospital's clinical laboratory using an electrode-sensitive assay (CA-25011, JEOL Ltd., Japan), and precision measurement and calibration are routinely conducted every day. Although data in 2009 were not available, the latest data of 30 measurements during September 2013 were available: the mean value of the lower-concentration standard solution widely used in Japan (mean value of the previous cumulative measurements using the same method at multiple centers in Japan, $132.37 \mathrm{mEq} / \mathrm{L}$ ) was $131.70 \pm$ $0.64 \mathrm{mEq} / \mathrm{L}$ (95\% confidence interval, 131.46-131.94), and that of the higher-concentration standard solution (mean value of the previous cumulative measurements at multiple centers in Japan, $150.05 \mathrm{mEq} / \mathrm{L}$ ) was $149.28 \pm$ $0.49 \mathrm{mEq} / \mathrm{L}$ (95\% confidence interval, 149.10-149.46). The sNa was adjusted with the paired serum glucose level if the serum glucose level was over $200 \mathrm{mg} / \mathrm{dL}(1.6 \mathrm{mEq} / \mathrm{L}$ per $100 \mathrm{mg} / \mathrm{dL}$ ) [18]. The mean of the 3 monthly measurements of body mass index (BMI), IDWL, and laboratory data was applied as each baseline value, with the exception of $\beta 2$-microglobulin ( $\beta 2-\mathrm{MG})$, which was measured routinely once in 3 months in all participants. Patients were followed from May 1, 2009 until transfer, kidney transplant, death, or study end on January 31, 2013.

This study protocol was approved by the ethics committee of Shuuwa General Hospital, and the study was preformed in accordance with the Declaration of Helsinki guidelines regarding ethical principles for medical research involving human subjects. Informed consent was obtained by all participants after information about the study was displayed in poster format in a public space.

\section{Outcomes}

The primary outcome was time to first infection-related hospitalization (IRH) after the 3rd laboratory measurement in July 2009. Events after the second event were not included in the analysis. IRH was defined when primary diagnosis on admission was infectious disease as noted in medical records. IRHs were divided into seven exclusive categories: pulmonary infections (e.g., pneumonia, bronchopneumonia), gastrointestinal infections (e.g., appendicitis, enterocolitis, cholecystitis, cholangitis), 
genitourinary infections (e.g., urinary tract infection, prostatitis), soft tissue infections (e.g., cellulitis), joint or bone infections (e.g., septic arthritis, osteomyelitis), septicemia, and others. Catheter-related bloodstream infection and graft infection were categorized as septicemia. The secondary outcome was death of any cause.

\section{Statistical analysis}

Data are described as means and standard deviations for continuous variables, or numbers and percentages for categorical variables. The association of baseline demographics and characteristics, or laboratory data with $\mathrm{sNa}$, was examined using univariate and multivariate linear regression analyses. In multivariate analyses, covariates included those that were statistically correlated with baseline sNa with $\mathrm{p}<0.05$ at univariate analyses. KaplanMeier curves were used for analysis of time to first IRH or death of any cause. Predictors of outcomes were evaluated using Cox hazards modeling adjusted for $\mathrm{sNa}$, all covariates, which were correlated to the outcomes with $\mathrm{p}<0.001$ at univariate analyses, and also the determinants of baseline $\mathrm{sNa}$ at multivariate linear regression analyses.

Statistical analyses were performed with Dr. SPSS II for Windows, a software package based on SPSS 11.0 J for Windows (SPSS, Chicago, IL, USA). P-values $<0.05$ were considered significant for all analyses.

\section{Results}

\section{General characteristics of participants}

In total, $332 \mathrm{HD}$ patients were enrolled into this study. The baseline demographics and characteristics are shown in Table 1 . The mean age of the study subjects was $61.6 \pm 12.6$ years, $36 \%$ of the study subjects were female, $36 \%$ were current or past smokers, $8 \%$ were not able to ambulate or transfer, $36 \%$ had diabetes mellitus

Table 1 Baseline demographics and characteristics of the study participants

\begin{tabular}{|c|c|c|c|c|}
\hline & \multirow[b]{2}{*}{ Whole group } & \multicolumn{3}{|c|}{ Serum sodium level tertile (mEq/L) } \\
\hline & & 1 st tertile $<138.0$ & 2nd tertile $138.0-140.0$ & 3rd tertile $>140.0$ \\
\hline Number of patients, $\mathrm{n}(\%)$ & $332(100)$ & $104(31)$ & $116(35)$ & $112(34)$ \\
\hline Age (years) & $61.6 \pm 12.6$ & $62.3 \pm 14.2$ & $60.6 \pm 12.0$ & $61.9 \pm 11.5$ \\
\hline Female, n (\%) & $121(36)$ & $34(33)$ & $41(35)$ & $46(41)$ \\
\hline Body mass index $\left(\mathrm{kg} / \mathrm{m}^{2}\right)$ & $21.2 \pm 3.6$ & $20.9 \pm 4.1$ & $21.2 \pm 3.4$ & $21.5 \pm 3.3$ \\
\hline Smoking history, n (\%) & $118(36)$ & $38(37)$ & $39(34)$ & $41(37)$ \\
\hline Inability to ambulate or transfer, n (\%) & $28(8)$ & $11(11)$ & $9(8)$ & $8(7)$ \\
\hline \multicolumn{5}{|l|}{ Comorbid conditions } \\
\hline Diabetes mellitus, n (\%) & $120(36)$ & $51(49)$ & $36(31)$ & $33(29)$ \\
\hline Hypertension, n (\%) & $310(93)$ & $100(96)$ & $105(91)$ & $105(94)$ \\
\hline Cardiovascular disease, n (\%) & $101(30)$ & $42(40)$ & $30(26)$ & $29(26)$ \\
\hline Peripheral vascular disease, n (\%) & $16(5)$ & $9(9)$ & $4(3)$ & $3(3)$ \\
\hline Cerebrovascular disease, n (\%) & $47(14)$ & $19(18)$ & $13(11)$ & $15(13)$ \\
\hline Chronic liver disease, n (\%) & $37(11)$ & $11(11)$ & $13(11)$ & $13(12)$ \\
\hline Cancer, n (\%) & $43(13)$ & $7(7)$ & $16(14)$ & $20(18)$ \\
\hline Dialysis vintage (months) & $124 \pm 96$ & $102 \pm 79$ & $135 \pm 94$ & $134 \pm 108$ \\
\hline IDWL (\% of body weight) & $5.1 \pm 1.3$ & $5.6 \pm 1.4$ & $5.0 \pm 1.3$ & $4.8 \pm 1.2$ \\
\hline \multicolumn{5}{|l|}{ Vascular access } \\
\hline Fistula & $290(87)$ & $88(85)$ & $103(89)$ & $99(88)$ \\
\hline Graft & $38(12)$ & $16(15)$ & $12(10)$ & $10(9)$ \\
\hline Catheter & $4(1)$ & $0(0)$ & $1(1)$ & $3(3)$ \\
\hline \multicolumn{5}{|l|}{ Laboratory data } \\
\hline Serum sodium (mEg/L) & $138.9 \pm 2.6$ & $136.0 \pm 1.8$ & $139.0 \pm 0.7$ & $141.5 \pm 1.1$ \\
\hline Hemoglobin (g/dL) & $10.5 \pm 0.9$ & $10.7 \pm 1.1$ & $10.5 \pm 0.9$ & $10.4 \pm 0.8$ \\
\hline Serum albumin (g/dL) & $3.8 \pm 0.3$ & $3.8 \pm 0.3$ & $3.9 \pm 0.3$ & $3.8 \pm 0.3$ \\
\hline Serum creatinine $(\mathrm{mg} / \mathrm{dL})$ & $11.7 \pm 2.8$ & $11.4 \pm 3.0$ & $12.1 \pm 2.8$ & $11.7 \pm 2.7$ \\
\hline Serum $\beta 2$-microglobulin (mg/dL) & $27.3 \pm 5.3$ & $28.0 \pm 4.9$ & $27.2 \pm 5.8$ & $26.6 \pm 5.1$ \\
\hline
\end{tabular}

Values are expressed as mean \pm SD for continuous variables, or numbers and percentages for categorical variables. Abbreviations: IDWL intradialytic weight loss. 
(DM), and 30\% had CVD. The study participants were categorized into three groups based on sNa; 1 st tertile: < $138.0 \mathrm{mEq} / \mathrm{L}, \mathrm{n}=104$; 2nd tertile: 138.0$140.0 \mathrm{mEq} / \mathrm{L}, \mathrm{n}=116$; 3rd tertile: $>140.0 \mathrm{mEq} / \mathrm{L}, \mathrm{n}=112$.

\section{Determinants of baseline serum sodium level}

In univariate linear regression analyses, DM, CVD, cancer, dialysis vintage, IDWL, hemoglobin, and serum albumin were correlated with baseline sNa (Table 2). In multivariate analyses, cancer and serum albumin were positively correlated, and IDWL and hemoglobin were negatively correlated with $\mathrm{sNa}$ (Table 2 ).

\section{Primary outcome}

During a mean follow-up of 39.5 months, 57 patients experienced at least one IRH (incidence rate: 56.4/1,000 patient-years overall; 89.7/1,000 in sNa 1st tertile; 57.9/ 1,000 in 2nd tertile; $28.0 / 1,000$ in 3rd tertile). The incidence rate of each IRH subtype is shown in Figure 1. Pulmonary infections were the most common type of infection among the HD patients in this study. The types of IRH having the highest incidence in the 1st tertile were observed to be pulmonary infections, gastrointestinal infections, genitourinary infections, and soft tissue infections.

The lower $\mathrm{sNa}$ tertiles were significantly associated with higher risk of IRH (Figure 2A). More IRH events occurred in the 1st and 2nd tertiles than in the 3rd tertile at univariate and multivariate Cox models (Table 3). When $\mathrm{sNa}$ was considered as a continuous variable, lower $\mathrm{sNa}$ was associated with higher risk of IRH (Table 3). CVD, and graft or catheter were also associated with increased risk of IRH.

\section{Secondary outcome}

During follow-up, 68 patients died. The association of sNa tertile with all-cause mortality was statistically significant (Figure 2B). When $\mathrm{sNa}$ was considered as a continuous variable, the relationship between lower $\mathrm{sNa}$ and higher all-cause mortality was observed in Cox models

Table 2 Determinants of baseline serum sodium level

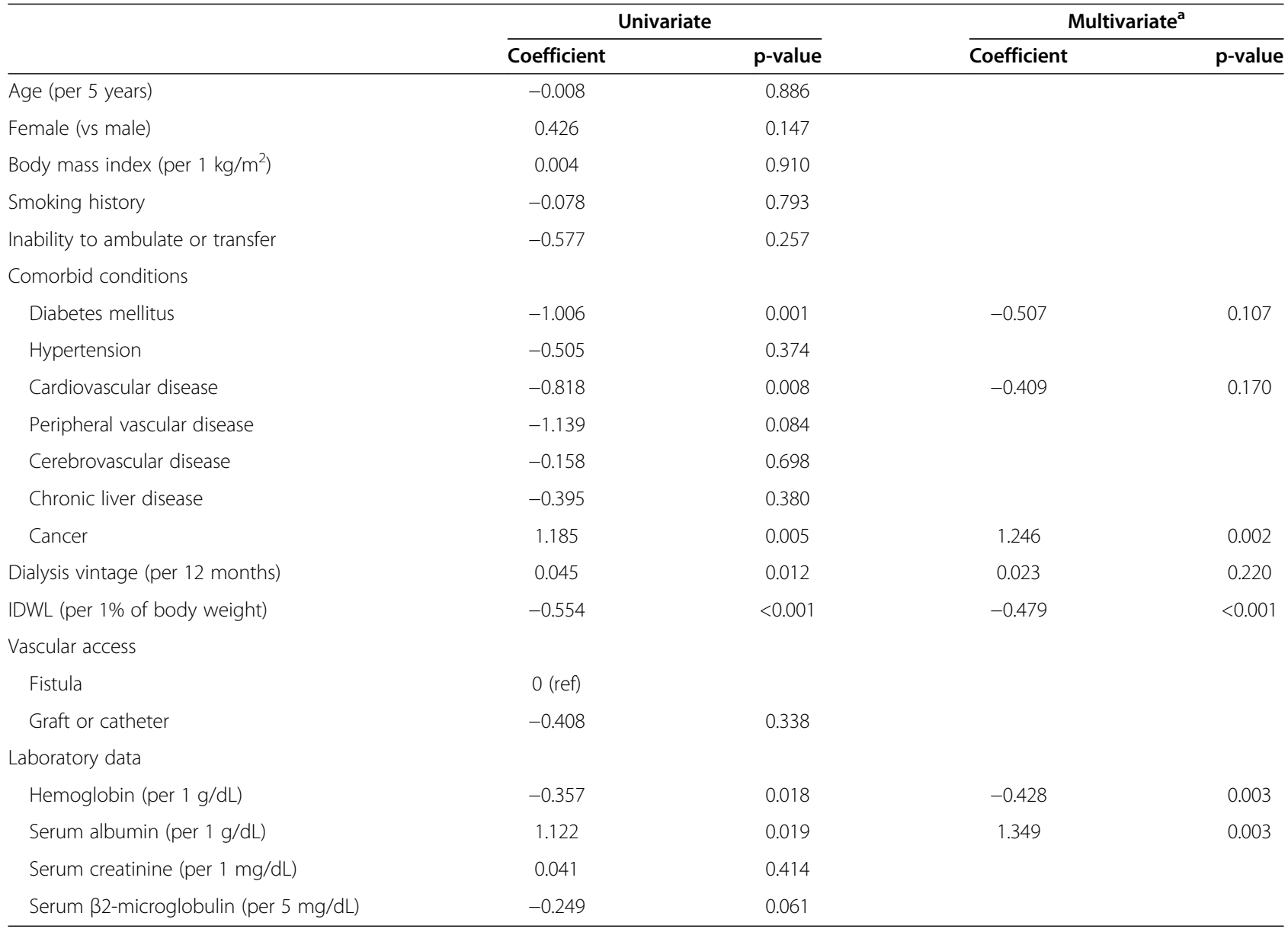

${ }^{a}$ Adjustments in all covariates, which were significantly correlated with baseline serum sodium level, with $\mathrm{p}<0.05$ at univariate analyses including diabetes mellitus, cardiovascular disease, cancer, dialysis vintage, IDWL, hemoglobin, and serum albumin.

Abbreviations: IDWL intradialytic weight loss. 


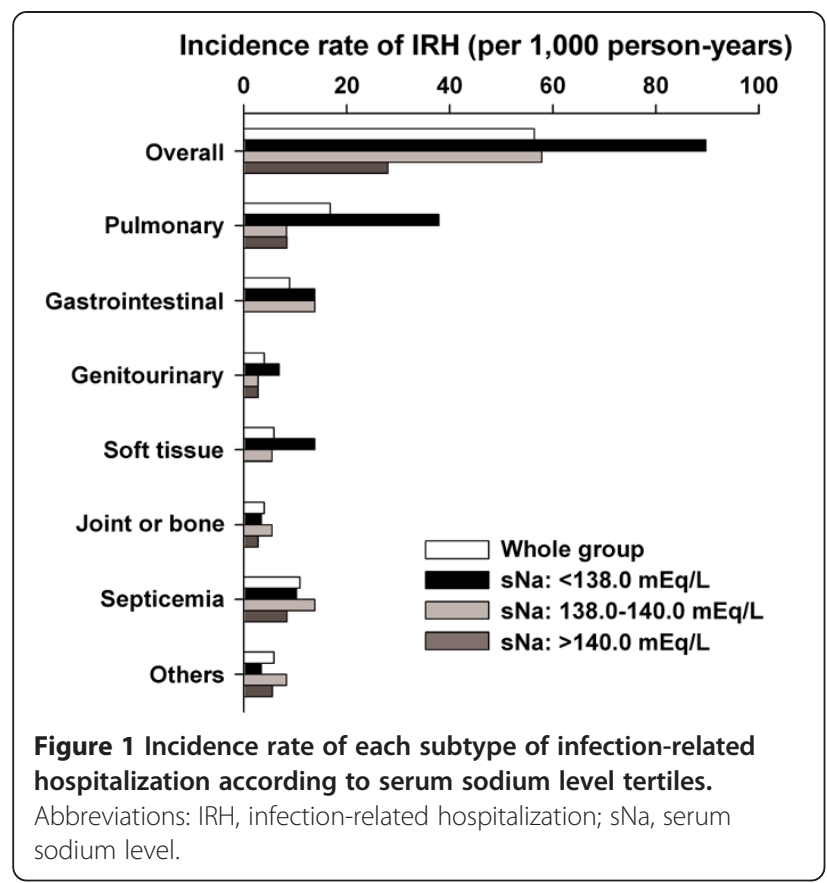

(Table 4). Older age, DM, and cancer were also associated with increased all-cause mortality. The association of CVD with increased all-cause mortality was marginally significant.

\section{Discussion}

The principal finding in the current study is that lower $\mathrm{sNa}$ is an independent predictor of higher risk for infection-related hospitalization in maintenance HD patients. To the best of our knowledge, this study is the first to investigate the relationship between $\mathrm{sNa}$ and risk of infection in patients with ESRD. Although increasing evidence indicates a possible causal relationship between $\mathrm{sNa}$ and mortality, specific pathogenesis or diseases contributing to mortality in the hyponatremic population have yet to be clarified. Infectious disease may partially account for the increased mortality observed in hyponatremic subjects with ESRD.

The present study showed that lower sNa is an independent predictor of higher risk for infection in ESRD patients, and confirmed the established relationship between lower $\mathrm{sNa}$ and higher mortality, even after adjustments for various covariates. Prior studies have shown an association between hyponatremia and increased mortality in a wide variety of diseases [3-11]. However, in the majority of these studies, baseline $\mathrm{sNa}$ was based on measurements during hospitalization and/or in the acute phase of underlying disease, and these settings are more likely to increase either an appropriate or inappropriate secretion of arginine vasopressin (antidiuretic hormone, $\mathrm{ADH}$ ), resulting in higher reabsorption of solute-free water with a lower level of sNa. In contrast,

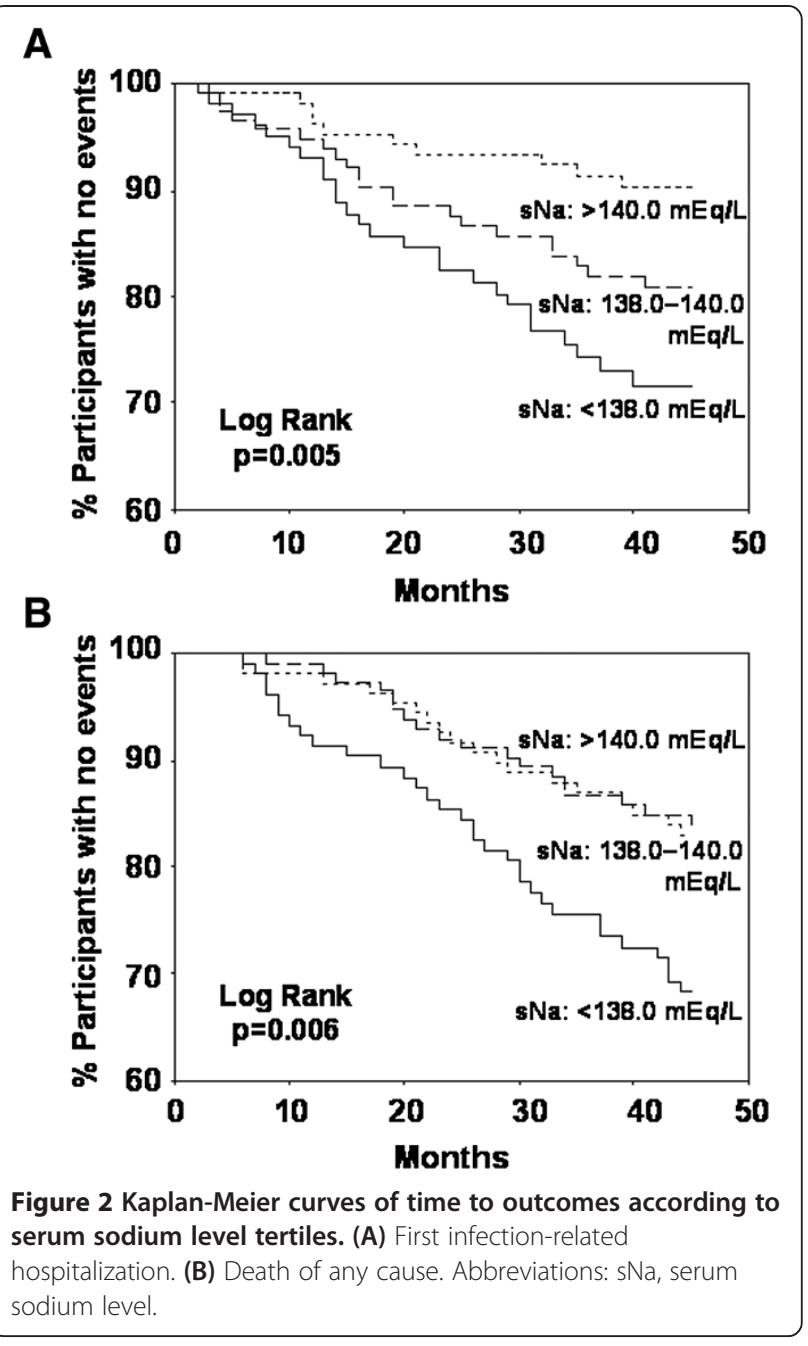

recent large cohort studies in the general population $[19,20]$ or in CKD patients [17] have shown that chronic and mild hyponatremia are associated with increased allcause mortality, even after adjustments for potential confounders or underlying disease. Furthermore, Waikar et al. [14] showed a continuous relationship between lower $\mathrm{sNa}$ and higher mortality in the HD population without residual renal function, indicating that this relationship is independent of $\mathrm{ADH}$ secretion related to underlying disease. Thus, it is possible that hyponatremia is not only a marker of severe underlying disease that results in poor outcome, but is also a direct contributor to mortality [21]. Similarly, our findings from the HD population suggest that hyponatremia possibly results in increased susceptibility to infection, and infectious disease additionally contributes increased mortality in hyponatremic subjects with ESRD. Although several studies of the HD population have not clarified specific diseases that are responsible for increased mortality in hyponatremic subjects [14-16], the HEMO study showed that the relationship between lower $\mathrm{sNa}$ and higher 
Table 3 Predictors of infection-related hospitalization in the study population

\begin{tabular}{|c|c|c|c|c|}
\hline & \multicolumn{2}{|c|}{ Univariate } & \multicolumn{2}{|c|}{ Multivariate $^{a}$} \\
\hline & HR $(95 \% \mathrm{Cl})$ & p-value & $\mathrm{HR}(95 \% \mathrm{Cl})$ & p-value \\
\hline \multicolumn{5}{|l|}{ Serum sodium level } \\
\hline \multicolumn{5}{|l|}{ Categorical model } \\
\hline$<138.0 \mathrm{mEq} / \mathrm{L}$ & $3.20(1.54-6.64)$ & 0.002 & $2.36(1.10-5.04)$ & 0.027 \\
\hline $138.0-140.0 \mathrm{mEq} / \mathrm{L}$ & $2.07(0.98-4.40)$ & 0.058 & $2.11(0.99-4.51)$ & 0.054 \\
\hline$>140.0 \mathrm{mEq} / \mathrm{L}$ & 1 (ref) & & 1 (ref) & \\
\hline Continuous model (per 1 mEq/L) & $0.86(0.79-0.94)$ & $<0.001$ & $0.90(0.81-0.99)$ & 0.040 \\
\hline Age (per 5 years) & $1.06(0.95-1.18)$ & 0.318 & & \\
\hline Female (vs male) & $1.31(0.78-2.22)$ & 0.313 & & \\
\hline Body mass index (per $1 \mathrm{~kg} / \mathrm{m}^{2}$ ) & $0.99(0.91-1.07)$ & 0.711 & & \\
\hline Smoking history & $1.52(0.90-2.56)$ & 0.120 & & \\
\hline Inability to ambulate or transfer & $4.79(2.61-8.80)$ & $<0.001$ & $2.10(0.90-4.91)$ & 0.086 \\
\hline \multicolumn{5}{|l|}{ Comorbid conditions } \\
\hline Diabetes mellitus & $1.66(0.99-2.80)$ & 0.056 & & \\
\hline Hypertension & $0.65(0.28-1.51)$ & 0.313 & & \\
\hline Cardiovascular disease & $2.54(1.51-4.27)$ & $<0.001$ & $2.21(1.30-3.75)$ & 0.003 \\
\hline Peripheral vascular disease & $1.83(0.66-5.07)$ & 0.243 & & \\
\hline Cerebrovascular disease & $1.65(0.86-3.19)$ & 0.135 & & \\
\hline Chronic liver disease & $1.08(0.49-2.39)$ & 0.846 & & \\
\hline Cancer & $1.01(0.46-2.23)$ & 0.976 & & \\
\hline Dialysis vintage (per 12 months) & $0.98(0.95-1.01)$ & 0.242 & & \\
\hline IDWL (per $1 \%$ of body weight) & $1.05(0.86-1.28)$ & 0.651 & & \\
\hline \multicolumn{5}{|l|}{ Vascular access } \\
\hline Fistula & 1 (ref) & & 1 (ref) & \\
\hline Graft or catheter & $4.08(2.33-7.15)$ & $<0.001$ & $2.95(1.57-5.55)$ & 0.001 \\
\hline \multicolumn{5}{|l|}{ Laboratory data } \\
\hline Hemoglobin (per 1 g/dL) & $0.80(0.59-1.08)$ & 0.140 & & \\
\hline Serum albumin (per $1 \mathrm{~g} / \mathrm{dL}$ ) & $0.16(0.07-0.37)$ & $<0.001$ & $0.47(0.15-1.45)$ & 0.186 \\
\hline Serum creatinine (per 1 mg/dL) & $0.84(0.76-0.92)$ & $<0.001$ & $0.97(0.86-1.10)$ & 0.654 \\
\hline Serum $\beta 2$-microglobulin (per 5 mg/dL) & $1.26(1.01-1.57)$ & 0.037 & & \\
\hline
\end{tabular}

${ }^{a}$ Adjustments in serum sodium level, all covariates, which were correlated with the outcome, with $p<0.001$ at univariate analyses including inability to ambulate or transfer, cardiovascular disease, graft or catheter, serum albumin, and serum creatinine, and also determinants of baseline serum sodium level at multivariate linear regression analyses including cancer, IDWL, and hemoglobin.

Abbreviations: $\mathrm{Cl}$ confidence interval, $H R$ hazard ratio, IDWL intradialytic weight loss.

mortality was not significant in analyses of cardiovascular mortality, but rather, was significant in analyses of non-cardiovascular mortality [14]. The findings of the present study may explain these observations.

Hyponatremia is a relatively frequent complication observed in infectious disease, especially in tuberculosis [22], pneumonia [11], human immunodeficiency virus infection [23], and bacterial meningitis [24], and the association of hyponatremia with increased mortality in these diseases has been identified. It is well known that infection can result in hyponatremia through various pathopysiological mechanisms including hypovolemia, hyperglycemia, renal failure, heart failure, or syndrome of inappropriate $\mathrm{ADH}$ secretion, but it has been unknown whether the existence of hyponatremia predicts infection. Of note is that the findings of the present study showed that subjects with lower sNa are more likely to develop infectious disease, although the study population was specific. Previously, a number of studies examined risk factors for IRH or infectious death in ESRD patients, but no studies considered $\mathrm{sNa}$ as a covariate related to risk for infection. However, the present study included almost all covariates that are known risk factors including age [25-28], DM [25-27], CVD [26], inability to ambulate or transfer [26], vascular access [25], hemoglobin [26], serum albumin [25-28], and serum 
Table 4 Predictors of all-cause mortality in the study population

\begin{tabular}{|c|c|c|c|c|}
\hline & \multicolumn{2}{|c|}{ Univariate } & \multicolumn{2}{|c|}{ Multivariate $^{a}$} \\
\hline & HR $(95 \% \mathrm{Cl})$ & p-value & $\mathrm{HR}(95 \% \mathrm{Cl})$ & p-value \\
\hline \multicolumn{5}{|l|}{ Serum sodium level } \\
\hline \multicolumn{5}{|l|}{ Categorical model } \\
\hline$<138.0 \mathrm{mEq} / \mathrm{L}$ & $2.06(1.15-3.66)$ & 0.014 & $1.57(0.85-2.87)$ & 0.148 \\
\hline $138.0-140.0 \mathrm{mEq} / \mathrm{L}$ & $0.94(0.49-1.81)$ & 0.853 & $0.97(0.50-1.89)$ & 0.938 \\
\hline$>140.0 \mathrm{mEq} / \mathrm{L}$ & 1 (ref) & & 1 (ref) & \\
\hline Continuous model (per 1 mEq/L) & $0.87(0.81-0.95)$ & 0.001 & $0.91(0.83-1.00)$ & 0.049 \\
\hline Age (per 5 years) & $1.40(1.25-1.57)$ & $<0.001$ & $1.24(1.08-1.41)$ & 0.002 \\
\hline Female (vs male) & $0.76(0.46-1.28)$ & 0.302 & & \\
\hline Body mass index (per $1 \mathrm{~kg} / \mathrm{m}^{2}$ ) & $0.88(0.81-0.95)$ & 0.001 & & \\
\hline Smoking history & $1.32(0.81-2.13)$ & 0.267 & & \\
\hline Inability to ambulate or transfer & $4.13(2.32-7.36)$ & $<0.001$ & $1.44(0.69-2.99)$ & 0.328 \\
\hline \multicolumn{5}{|l|}{ Comorbid conditions } \\
\hline Diabetes mellitus & $2.80(1.73-4.54)$ & $<0.001$ & $1.98(1.17-3.36)$ & 0.011 \\
\hline Hypertension & $1.66(0.52-5.30)$ & 0.388 & & \\
\hline Cardiovascular disease & $2.36(1.47-3.80)$ & $<0.001$ & $1.65(0.98-2.76)$ & 0.059 \\
\hline Peripheral vascular disease & $3.84(1.90-7.75)$ & $<0.001$ & $1.89(0.88-4.06)$ & 0.104 \\
\hline Cerebrovascular disease & $2.07(1.18-3.63)$ & 0.011 & & \\
\hline Chronic liver disease & $1.63(0.85-3.10)$ & 0.140 & & \\
\hline Cancer & $2.82(1.65-4.84)$ & $<0.001$ & $2.49(1.39-4.46)$ & 0.002 \\
\hline Dialysis vintage (per 12 months) & $0.99(0.95-1.02)$ & 0.357 & & \\
\hline IDWL (per $1 \%$ of body weight) & $1.02(0.85-1.23)$ & 0.824 & & \\
\hline \multicolumn{5}{|l|}{ Vascular access } \\
\hline Fistula & 1 (ref) & & & \\
\hline Graft or catheter & $2.14(1.20-3.79)$ & 0.010 & & \\
\hline \multicolumn{5}{|l|}{ Laboratory data } \\
\hline Hemoglobin (per 1 g/dL) & $0.82(0.62-1.07)$ & 0.140 & & \\
\hline Serum albumin (per $1 \mathrm{~g} / \mathrm{dL}$ ) & $0.16(0.08-0.32)$ & $<0.001$ & $0.65(0.24-1.74)$ & 0.388 \\
\hline Serum creatinine (per 1 mg/dL) & $0.76(0.69-0.83)$ & $<0.001$ & $0.93(0.81-1.06)$ & 0.272 \\
\hline Serum $\beta 2$-microglobulin (per 5 mg/dL) & $1.26(1.03-1.54)$ & 0.027 & & \\
\hline
\end{tabular}

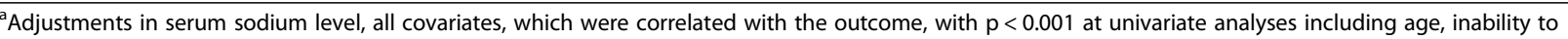
ambulate or transfer, diabetes mellitus, cardiovascular disease, peripheral vascular disease, cancer, serum albumin, and serum creatinine, and also determinants of baseline serum sodium level at multivariate linear regression analyses including IDWL and hemoglobin.

Abbreviations: $\mathrm{Cl}$ confidence interval, $H R$ hazard ratio, IDWL intradialytic weight loss.

ß2-MG [28]. A few studies in hospitalized patients have shown that hyponatremia can be a risk of infection, but the data are very limited. In an analysis of perioperative patients, preoperative hyponatremia predicted wound infections and pneumonia [12]. Jensen et al. showed that hyponatremia was one of the risks factors for hospital-acquired Staphylococcus aureus bacteremia in hospitalized patients [29]. There is a need for further studies to investigate the relationship between $\mathrm{sNa}$ and risk of infection also in the general population.

A key question is whether hyponatremia is merely a marker of severe comorbidities, or is a direct contributor to mortality; similarly, it remains unknown whether hyponatremia is merely an indicator of decreased immunological defense related to underlying disease, or results in increased susceptibility to infection. The present observational study could not answer this question. Given that data on urine output for each participant in the present study were not available, patients whose HD vintage was less than 12 months were excluded to decrease the influence of residual renal function with $\mathrm{ADH}$ secretion related to underlying disease on sNa. Nonetheless, residual confounders may have remained. An interventional study controlling for $\mathrm{sNa}$ is particularly difficult in ESRD patients, given that a vasopressin V2receptor antagonist is not effective in oligoanuric subjects, 
or that a change in the dialysate sodium level does not influence pre-dialytic sNa [16]. There are several possible explanations for the pathophysiological link between $\mathrm{sNa}$ and susceptibility to infection. First, cellular edema of mucosal membrane associated with extracellular hypotonicity and water transfer into the intracellular space may result in decreased microbial barrier function of the mucosa in the respiratory, gastrointestinal, or urinary tract, given that infections of these organs were more frequent in the lower sNa tertile group in the present study (Figure 1). Second, decreased function of $\mathrm{T}_{\mathrm{H}} 17$ cells (interleukin-17 (IL-17)-producing helper $\mathrm{T}$ cells) may be related. $\mathrm{T}_{\mathrm{H}} 17$ cells and IL-17 play an important role in host immunity, with the capacity of protection against extracellular pathogens and fungi, whereas they are also important drivers of autoimmune disease, and have inflammatory properties. A recent study showed that elevated sodium chloride concentration promoted the differentiation of $\mathrm{CD}^{+} \mathrm{T}$ cells into $\mathrm{T}_{\mathrm{H}} 17$ cells in vitro, and a high-salt diet accelerated the development of autoimmune disease through the activation of $\mathrm{T}_{\mathrm{H}} 17$ cells in a mouse model [30]. Similarly, it is possible that elevated sodium chloride concentration increases protective function against microorganisms, whereas decreased sodium chloride concentration or hyponatremia can reduce it through inhibition of $\mathrm{T}_{\mathrm{H}} 17$ cells. Further studies are essential to examine the association of $\mathrm{sNa}$ with immunological parameters such as immunoglobulin levels, cytokine levels, or functions of immunocompetent cells including $\mathrm{T}_{\mathrm{H}} 17$ cells in order to clarify whether hyponatremia affects the immune system.

The current study had several limitations. First, this study was an observational, single-center study. Second, the sample size and the number of outcomes were limited, and may not be sufficient for generalization to a larger population. However, the mean $\mathrm{sNa}$ was almost comparable to that of the Japanese population according to the Dialysis Outcomes and Practice Patterns Study (DOPPS) [15], and our study population was representative of the Japanese HD population. The 1st tertile threshold value of $\mathrm{sNa}$ in this study was different from that in the DOPPS study [15], given the difference in mean sNa of the whole group. Similarly, the number of patients in the present study representing each subtype of IRH was limited, and it was not clear if the association of sNa with risk of IRH was independent of or specific for infection subtype (Figure 1). A larger cohort is needed to answer this question. Third, the relationship between $\mathrm{sNa}$ and risk of IRH in a long follow-up period was examined using only baseline $\mathrm{sNa}$ measurement. More than 3 monthly measurements of sNa were available during 6 months before IRH in all subjects who experienced IRH $(n=57)$, and the mean value of the 3 measurements available just before IRH was $137.4 \pm 2.8 \mathrm{mEq} / \mathrm{L}$.
Although this value was significantly lower than the baseline value $(137.9 \pm 2.4 \mathrm{mEq} / \mathrm{L})$ in the paired $t$-test, the difference was $0.5 \mathrm{mEq} / \mathrm{L}$. Furthermore, 21 patients out of 26 whose baseline $\mathrm{sNa}$ was $<138.0 \mathrm{mEq} / \mathrm{L}$ (1st sNa tertile) still had $\mathrm{sNa}<138.0 \mathrm{mEq} / \mathrm{L}$ just before IRH. Thus, the relationship between baseline $\mathrm{sNa}$ and risk of IRH would remain during a relatively long follow-up period. Fourth, data on dialysate sodium level for each participant were not available in the present study, and therefore were not included in the covariates. However, dialysate sodium level does not appear to determine pre-dialytic sNa [16], and it is controversial whether dialysate sodium level according to $\mathrm{sNa}$ is associated with mortality [15]. Finally, data on volume status that can influence sNa were limited. One to three monthly post-dialytic measurements of plasma brain natriuretic peptide were made from May to July 2009 in 257 of the 332 study patients. The mean values were $547 \pm 965,426 \pm 667$, and $370 \pm 401 \mathrm{pg} / \mathrm{mL}$ in the $1 \mathrm{st}$, 2nd, and 3rd tertiles, respectively. The differences among the three groups were not statistically significant, as assessed by the Kruskal-Wallis $\mathrm{H}$ test $(\mathrm{p}=0.446)$.

\section{Conclusions}

Lower $\mathrm{sNa}$ is an independent predictor of higher risk for infection-related hospitalization in maintenance HD patients. Infectious disease may partially account for the increased mortality observed in the hyponatremic population with ESRD.

\section{Abbreviations \\ ADH: Antidiuretic hormone; BMI: Body mass index; $\beta 2$-MG: $\beta 2$-microglobulin; $\mathrm{Cl}$ : Confidence interval; CKD: Chronic kidney disease; CVD: Cardiovascular disease; DM: Diabetes mellitus; DOPPS: The dialysis outcomes and practice patterns study; ESRD: End-stage renal disease; HD: Hemodialysis; HR: Hazard ratio; IDWL: Intradialytic weight loss; IL-17: Interleukin-17; IRH: Infection- related hospitalization; sNa: Serum sodium level; $T_{H} 17$ cells: Interleukin-17- producing helper T cells.}

\section{Competing interests}

The authors declare that they have no competing interests.

\section{Authors' contributions}

SM performed the study design and statistical analysis, and drafted the manuscript. MK participated in the study design and coordination, and critically revised the manuscript. YK, KK, TT, SS, and WA contributed to treatment of the patients and collection of data. SS provided expert opinion, and critically revised the manuscript. All authors read and approved the final manuscript.

\section{Acknowledgements}

We wish to thank all nursing and medical staff at our hemodialysis unit for their help and support. We are also grateful to all participants in this study.

\section{Author details}

'Department of Nephrology, Shuuwa General Hospital, 1200 Yaharashinden, Kasukabe, Saitama 344-0035, Japan. ${ }^{2}$ Department of Nephrology, Graduate School of Medicine, Tokyo Medical and Dental University, 1-5-45 Yushima, Bunkyo-ku, Tokyo 113-8519, Japan.

Received: 5 August 2013 Accepted: 16 December 2013

Published: 19 December 2013 


\section{References}

1. Waikar SS, Mount DB, Curhan GC: Mortality after hospitalization with mild, moderate, and severe hyponatremia. Am J Med 2009, 122:857-865.

2. Wald R, Jaber BL, Price LL, Upadhyay A, Madias NE: Impact of hospitalassociated hyponatremia on selected outcomes. Arch Intern Med 2010, 170:294-302.

3. Lee DS, Austin PC, Rouleau JL, Liu PP, Naimark D, Tu JV: Predicting mortality among patients hospitalized for heart failure: derivation and validation of a clinical model. JAMA 2003, 290:2581-2587.

4. Gheorghiade M, Rossi JS, Cotts W, Shin DD, Hellkamp AS, Piña IL, Fonarow GC, DeMarco T, Pauly DF, Rogers J, DiSalvo TG, Butler J, Hare JM, Francis GS, Stough WG, O'Connor CM: Characterization and prognostic value of persistent hyponatremia in patients with severe heart failure in the ESCAPE Trial. Arch Intern Med 2007, 167:1998-2005.

5. Gheorghiade M, Abraham WT, Albert NM, Gattis Stough W, Greenberg BH, O'Connor CM, She L, Yancy CW, Young J, Fonarow GC, OPTIMIZE-HF Investigators and Coordinators: Relationship between admission serum sodium concentration and clinical outcomes in patients hospitalized for heart failure: an analysis from the OPTIMIZE-HF registry. Eur Heart J 2007, 28:980-988.

6. Borroni G, Maggi A, Sangiovanni A, Cazzaniga M, Salerno F: Clinical relevance of hyponatraemia for the hospital outcome of cirrhotic patients. Dig Liver Dis 2000, 32:605-610.

7. Heuman DM, Abou-Assi SG, Habib A, Williams LM, Stravitz RT, Sanyal AJ, Fisher RA, Mihas AA: Persistent ascites and low serum sodium identify patients with cirrhosis and low MELD scores who are at high risk for early death. Hepatology 2004, 40:802-810.

8. Goldberg A, Hammerman H, Petcherski S, Nassar M, Zdorovyak A, Yalonetsky S, Kapeliovich M, Agmon Y, Beyar R, Markiewicz W, Aronson D: Hyponatremia and long-term mortality in survivors of acute ST-elevation myocardial infarction. Arch Intern Med 2006, 166:781-786.

9. Scherz N, Labarère J, Méan M, Ibrahim SA, Fine MJ, Aujesky D: Prognostic importance of hyponatremia in patients with acute pulmonary embolism. Am J Respir Crit Care Med 2010, 182:1178-1183.

10. Doshi SM, Shah P, Lei X, Lahoti A, Salahudeen AK: Lyponatremia in hospitalized cancer patients and its impact on clinical outcomes. Am J Kidney Dis 2012, 59:222-228.

11. Nair $\mathrm{V}$, Niederman MS, Masani N, Fishbane S: Hyponatremia in communityacquired pneumonia. Am J Nephrol 2007, 27:184-190.

12. Leung AA, McAlister FA, Rogers SO Jr, Pazo V, Wright A, Bates DW: Preoperative hyponatremia and perioperative complications. Arch Intern Med 2012, 172:1474-1481.

13. Funk GC, Lindner G, Druml W, Metnitz B, Schwarz C, Bauer P, Metnitz PG Incidence and prognosis of dysnatremias present on ICU admission. Intensive Care Med 2010, 36:304-311.

14. Waikar SS, Curhan GC, Brunelli SM: Mortality associated with low serum sodium concentration in maintenance hemodialysis. Am J Med 2011, 124:77-84.

15. Hecking M, Karaboyas A, Saran R, Sen A, Hörl WH, Pisoni RL, Robinson BM Sunder-Plassmann G, Port FK: Predialysis serum sodium level, dialysate sodium, and mortality in maintenance hemodialysis patients: the Dialysis Outcomes and Practice Patterns Study (DOPPS). Am J Kidney Dis 2012, 59:238-248

16. Mc Causland FR, Brunelli SM, Waikar SS: Dialysate sodium, serum sodium and mortality in maintenance hemodialysis. Nephrol Dial Transplant 2012 27:1613-1618.

17. Kovesdy CP, Lott EH, Lu JL, Malakauskas SM, Ma JZ, Molnar MZ, KalantarZadeh K: Hyponatremia, hypernatremia, and mortality in patients with chronic kidney disease with and without congestive heart failure. Circulation 2012, 125:677-684.

18. Katz MA: Hyperglycemia-induced hyponatremia-calculation of expected serum sodium depression. N Engl J Med 1973, 289:843-844.

19. Hoorn EJ, Rivadeneira F, van Meurs JB, Ziere G, Stricker BH, Hofman A, Pols HA, Zietse R, Uitterlinden AG, Zillikens MC: Mild hyponatremia as a risk factor for fractures: the Rotterdam Study. J Bone Miner Res 2011, 26:1822-1828.

20. Liamis G, Rodenburg EM, Hofman A, Zietse R, Stricker BH, Hoorn EJ: Electrolyte disorders in community subjects: prevalence and risk factors. Am J Med 2013, 126:256-263.

21. Hoorn EJ, Zietse R: Hyponatremia and mortality: moving beyond associations. Am J Kidney Dis 2013, 62:139-149.
22. Roca B, Tornador N, Tornador E: Presentation and outcome of tuberculous meningitis in adults in the province of Castellon, Spain: a retrospective study. Epidemiol Infect 2008, 136:1455-1462.

23. Tang WW, Kaptein EM, Feinstein El, Massry SG: Hyponatremia in hospitalized patients with the acquired immunodeficiency syndrome (AIDS) and the AIDS-related complex. Am J Med 1993, 94:169-174.

24. Chao YN, Chiu NC, Huang FY: Clinical features and prognostic factors in childhood pneumococcal meningitis. J Microbiol Immunol Infect 2008 41:48-53.

25. Powe NR, Jaar B, Furth SL, Hermann J, Briggs W: Septicemia in dialysis patients: incidence, risk factors, and prognosis. Kidney Int 1999, 55:1081-1090.

26. Dalrymple LS, Johansen KL, Chertow GM, Cheng SC, Grimes B, Gold EB Kaysen GA: Infection-related hospitalizations in older patients with ESRD. Am J Kidney Dis 2010, 56:522-530.

27. Aslam N, Bernardini J, Fried L, Burr R, Piraino B: Comparison of infectious complications between incident hemodialysis and peritoneal dialysis patients. Clin J Am Soc Nephrol 2006, 1:1226-1233.

28. Cheung AK, Greene T, Leypoldt JK, Yan G, Allon M, Delmez J, Levey AS, Levin NW, Rocco MV, Schulman G, Eknoyan G, HEMO Study Group: Association between serum 2-microglobulin level and infectious mortality in hemodialysis patients. Clin J Am Soc Nephrol 2008, 3:69-77.

29. Jensen AG, Wachmann $C H$, Poulsen KB, Espersen F, Scheibel J, Skinhøj P, Frimodt-Møller N: Risk factors for hospital-acquired Staphylococcus aureus bacteremia. Arch Intern Med 1999, 159:1437-1444

30. Kleinewietfeld M, Manzel A, Titze J, Kvakan H, Yosef N, Linker RA, Muller DN, Hafler DA: Sodium chloride drives autoimmune disease by the induction of pathogenic TH17 cells. Nature 2013, 496:518-522.

doi:10.1186/1471-2369-14-276

Cite this article as: Mandai et al:: Lower serum sodium level predicts higher risk of infection-related hospitalization in maintenance hemodialysis patients: an observational cohort study. BMC Nephrology $201314: 276$

\section{Submit your next manuscript to BioMed Central and take full advantage of:}

- Convenient online submission

- Thorough peer review

- No space constraints or color figure charges

- Immediate publication on acceptance

- Inclusion in PubMed, CAS, Scopus and Google Scholar

- Research which is freely available for redistribution 